\title{
Penetrating cardiac injury
}

\author{
PL Tahalele*, Puruhito, A Prasmono, H Kusbijanto, H Soebroto, YE Sembiring \\ From 23rd World Congress of the World Society of Cardio-Thoracic Surgeons \\ Split, Croatia. 12-15 September 2013
}

\section{Background}

Penetrating cardiac injury has the highest mortality and morbidity rates of all organ injury. The prehospital mortality rate for penetrating cardiac injury was $70-80 \%$. Prehospital care including rapid transportation of patients to trauma center and agresive intervention has increased survival rate.

The purpose of this study was to show our experience in treatment of patient with penetrating injury to the cardiac.

\section{Methods}

This is retrospective studies from 1985 to 2011 (26 years) at emergency room Dr. Soetomo General Hospital reporting of 47 patients with penetrating injury to the cardiac.

\section{Results}

In this review we have defined 47 patients with male 36 patients $(76.59 \%)$ and female 11 patients $(23.40 \%)$. Age is ranged from 9-64 years. The mechanism of injury consist: stab wound (knife, stiletto) 35 patients (74.47\%), air rifle (bullet) 5 patients $(10.64 \%)$, segment fracture of the rib one patient ( $2.12 \%)$ and CVP catheter one patient (2.12). The injured site are Right Ventricle 30 patients (63.83\%), Left Ventricle 5 patients (10.63\%), Right Atrium 4 patients (8.51\%), Ascending Aorta one patients (2.12 \%), and Pulmonary Artery 1 patients (2.12\%).

There were 5 major complications: icterus in 14 patients (29.78\%), wound dehiscent in one patient (2.12\%), sepsis in one patient $(2.12 \%)$, VSD in one patient $(2.12 \%)$, mortality in 5 patients $(10.63 \%)$. The surviving is 42 patients (89.36\%).

\footnotetext{
* Correspondence: pltahalele@yahoo.com Department of Surgery Division of Cardiothoracic and Vascular Surgery School of Medicine Airlangga University - Dr. Soetomo General Hospital
} Surabaya, Indonesia

C 2013 Tahalele et al; licensee BioMed Central Ltd. This is an Open Access article distributed under the terms of the Creative Commons Attribution License (http://creativecommons.org/licenses/by/2.0), which permits unrestricted use, distribution, and reproduction in any medium, provided the original work is properly cited.

\section{Conclusion}

The result of our experience has been satisfactory in all cases. Because of this experience, we recommend aggressive thoracotomy exploration to lower operative mortality and morbidity.

Published: 11 September 2013

Cite this article as: Tahalele et al:: Penetrating cardiac injury. Journal of Cardiothoracic Surgery 2013 8(Suppl 1):P41.
doi:10.1186/1749-8090-8-S1-P41 and take full advantage of:

- Convenient online submission

- Thorough peer review

- No space constraints or color figure charges

- Immediate publication on acceptance

- Inclusion in PubMed, CAS, Scopus and Google Scholar

- Research which is freely available for redistribution 